\title{
Effect of the French Oak Wood Extract Robuvit on Markers of Oxidative Stress and Activity of Antioxidant Enzymes in Healthy Volunteers: A Pilot Study
}

\author{
Martina Horvathova, ${ }^{1}$ Zuzana Orszaghova, ${ }^{1}$ Lucia Laubertova, ${ }^{1,2}$ Magdalena Vavakova, \\ Peter Sabaka, ${ }^{3}$ Peter Rohdewald, ${ }^{4}$ Zdenka Durackova, ${ }^{1}$ and Jana Muchova ${ }^{1}$ \\ ${ }^{1}$ Institute of Medical Chemistry, Biochemistry and Clinical Biochemistry, Faculty of Medicine, Comenius University, \\ Sasinkova 2, 81108 Bratislava, Slovakia \\ ${ }^{2}$ Institute of Medical Biochemistry, Jessenius Faculty of Medicine, Comenius University, Malá Hora 4, 03601 Martin, Slovakia \\ ${ }^{3}$ 2nd Department of Internal Medicine, Faculty of Medicine, Comenius University, Mickiewiczova 13, 81369 Bratislava, Slovakia \\ ${ }^{4}$ Westfälische Wilhelms-Universität Münster, Institut für Pharmazeutische Chemie, Twenteweg 15, 48161 Münster, Germany
}

Correspondence should be addressed to Jana Muchova; jana.muchova@fmed.uniba.sk

Received 18 June 2014; Accepted 8 August 2014; Published 31 August 2014

Academic Editor: Cristina Angeloni

Copyright (C) 2014 Martina Horvathova et al. This is an open access article distributed under the Creative Commons Attribution License, which permits unrestricted use, distribution, and reproduction in any medium, provided the original work is properly cited.

\begin{abstract}
We examined in vitro antioxidant capacity of polyphenolic extract obtained from the wood of oak Quercus robur (QR), Robuvit, using TEAC (Trolox equivalent antioxidant capacity) method and the effect of its intake on markers of oxidative stress, activity of antioxidant enzymes, and total antioxidant capacity in plasma of 20 healthy volunteers. Markers of oxidative damage to proteins, DNA, and lipids and activities of $\mathrm{Cu} / \mathrm{Zn}$-superoxide dismutase (SOD), catalase (CAT), and glutathione peroxidase (GPx) were determined in the erythrocytes. We have found an in vitro antioxidant capacity of Robuvit of 6.37 micromole Trolox equivalent/mg of Robuvit. One month intake of Robuvit in daily dose of $300 \mathrm{mg}$ has significantly decreased the serum level of advanced oxidation protein products (AOPP) and lipid peroxides (LP). Significantly increased activities of SOD and CAT as well as total antioxidant capacity of plasma after one month intake of Robuvit have been shown. In conclusion, we have demonstrated for the first time that the intake of Robuvit is associated with decrease of markers of oxidative stress and increase of activity of antioxidant enzymes and total antioxidant capacity of plasma in vivo.
\end{abstract}

\section{Introduction}

The French oak wood extract Robuvit (Horpag Research Ltd.) is a registered proprietary water extract obtained from the wood of Quercus robur (QR). The plant belongs to the plant family Fagacae, genus Quercus.

The oak wood used for Robuvit originates exclusively from oak trees grown in France. Oak wood contains a specific profile of tannins named roburins that are part of the ellagitannins (ETs). Robuvit is standardized and specified to contain at least $20 \%$ of roburins (A, B, C, D, and E) including grandinin. The two most abundant ETs in the Robuvit are stereoisomers vescalagin and castalagin, which were originally isolated and described by Mayer et al. [1].
Roburins and grandinin are dimers of these compounds or differ by the presence of a pentose substituent. They were isolated and identified later by du Penhoat et al. [2]. Further to the roburins, Robuvit contains monomeric vescalagin and castalagin as well as ellagic acid (EA) and gallic acid (GA) [3].

Owing to their unique molecular structure roburins are very potent antioxidants. Humans have been exposed to these compounds for centuries from wine and spirits that matured in oak wood barrels. Oak wood is currently the only known food source of roburins, and, according to this specificity, the major source of roburins in human diets results from the consumption of wine and spirits (cognac and whiskey) traditionally matured, aged, and stored in oak barrels [4]. 
Little is known about roburins bioavailability and biological effects. Natella et al. [3] found out that Robuvit is bioavailable to humans and its consumption is associated with increase of antioxidant capacity at hydrophilic conditions. They identified beside GA and EA also metabolites of ETs named urolithins in the plasma of volunteers after intake of Robuvit. Urolithins are metabolites of EA, which are released from ETs by hydrolysis in the intestine by gut microflora [5]. Effects of EA, one of compounds of Robuvit, were examined in many models in vitro and in vivo. EA is characterized by antioxidant [6-9], anticarcinogenic [10-13], antiproliferative $[9,14]$, anti-inflammatory $[15,16]$, proapoptotic [17], and antiplatelet properties [18].

The aim of our study was to examine in vitro antioxidant capacity of Robuvit using TEAC method and the in vivo effect of its intake on oxidative stress in healthy volunteers. The level of markers of oxidative stress (markers of oxidative damage to proteins, lipids, and DNA), activities of antioxidant enzymes $\mathrm{Cu} / \mathrm{Zn}$-superoxide dismutase (SOD), catalase (CAT), and glutathione peroxidase $(\mathrm{GPx})$ and total antioxidant capacity of plasma were investigated.

\section{Material and Methods}

2.1. Subjects. Twenty healthy volunteers (12 women and 8 men, mean age $54.2 \pm 6.56$; range: $45-65$ years) were included in the study. All participants gave a written informed agreement to participate in the study. The study was approved by the Ethical Committee of University Hospital and Faculty of Medicine, Comenius University in Bratislava, Slovakia. Subjects with acute inflammatory, renal and cardiovascular diseases, and diabetes mellitus and women with hormone substitution therapy were excluded from the study.

The 8-week experiment was divided into three periods. In the first period (run-in period) volunteers were instructed to control their diet for 2 weeks. No additional antioxidants like vitamins C, E or coenzyme Q or excess of chocolate, red wine, or beer should be consumed. Drinking a cup of green tea, $2 \mathrm{dL}$ red wine, or 1 beer daily was allowed. After run-in period, Robuvit administration began (week 0). Volunteers took 1 capsule $(100 \mathrm{mg}$ ) of extract Robuvit three times a day (300 mg daily) for 4 weeks, followed by two-week wash-out period in which capsules were not administered. The extract was supplied by Horphag Research Ltd., Switzerland.

2.2. Sample Preparation. The venous blood was collected after 12-hour overnight fast into commercial serum tubes and EDTA coated tubes. Within 1 hour of collection, blood was centrifuged $(700 \times \mathrm{g}, 5 \mathrm{~min})$; serum and plasma were aliquoted and frozen at $-80^{\circ} \mathrm{C}$ until analysis. For isolation of erythrocytes, blood was washed three times with $0.15 \mathrm{~mol} / \mathrm{L}$ $\mathrm{NaCl}$ solution. After final centrifugation $(700 \times \mathrm{g}, 7 \mathrm{~min})$, erythrocytes were haemolysed by addition of triple volume of distilled water and haemolysate was frozen at $-20^{\circ} \mathrm{C}$ until analysis.

The samples of blood were taken after run-in period (week 0), at the end of intervention period (week 4) and at the end of wash-out period (week 6).
In the serum of the basic biochemical parameters, the concentrations of advanced oxidation protein products (AOPP) and lipid peroxides (LP) were determined; in the plasma the levels of advanced glycation end-products (AGEs), 8-isoprostanes (8-isoP), protein carbonyls, and total antioxidant capacity were examined. In isolated lymphocytes marker of oxidative damage to DNA and 8-oxoguanin (8oxoG) was assessed. The concentration of haemoglobin by Drabkin method and SOD, CAT, and GPx activities were measured in haemolysate of erythrocytes.

2.3. Chemicals. ABTS $\left[2,2^{\prime}\right.$-azinobis-(3-ethylbenzothiazoline-6-sulfonic acid) diammonium salt], Trolox (6-hydroxy2,5,7,8-tetramethylchroman-2-carboxylic acid), dextran sulphate, chloramine $\mathrm{T}$, igepal, o-phenylenediamine, guanidine hydrochloride, Tween 20, bovine serum albumin (BSA), histopaque 1083, low melting point (LMP) agarose, normal melting point (NMP) agarose, Triton X-100, hydrogen peroxide, AAPH [2,2' -azobis (2-amidinopropane) dihydrochloride], and formamidopyrimidine-DNA glycosylase (Fpg) were purchased from Sigma-Aldrich (USA); sodium azide and DAPI (4,6-diamidino-2-phenylindole dihydrochloride) were purchased from Merck (Germany); TPTZ (2,4,6-tripyridyl-s-triazine), disodium fluorescein, 2,4-dinitrophenylhydrazine (DNPH), and glycerol were purchased from Fluka (Germany); all other chemicals were purchased from Lachema (Czech republic); Robuvit was obtained from Horphag Research Ltd. (Geneva, Switzerland).

2.4. Measurement of Basic Biochemical Parameters. Basic biochemical parameters (bilirubin, glucose, gamma-glutamyl transferase (GMT), alkaline phosphatase (ALP), aspartate aminotransferase (AST), alanine aminotransferase (ALT), uric acid (UA), total proteins (TP), total cholesterol (TCh), triacylglycerols (TAG), HDL-cholesterol (HDL-chol), LDLcholesterol (LDL-chol), and VLDL-cholesterol (VLDL-chol)) were determined at an accredited clinical biochemistry and haematology laboratory using a Hitachi 911 analyzer by Roche diagnostics kits (Switzerland).

2.5. Measurement of In Vitro Antioxidant Capacity of Robuvit-TEAC (Trolox Equivalent Antioxidant Capacity) Assay. $57.8 \mathrm{mg}$ of Robuvit was dissolved in $10 \mathrm{~mL}$ of distilled water, vortexed for $5 \mathrm{~min}$, centrifuged $(3000 \times \mathrm{g} / 10 \mathrm{~min})$, and diluted to concentrations of $10^{-4}$ to $10^{-9} \mathrm{~g} / \mathrm{mL}$ with distilled water.

In vitro antioxidant capacity of Robuvit was measured by method according to $\mathrm{Re}$ et al. [19]. It is a decolourization assay for measurement of both lipophilic and hydrophilic antioxidants. The radical monocation of $2,2^{\prime}$-azinobis(3-ethylbenzothiazoline-6-sulfonic acid) diammonium salt $\left(\mathrm{ABTS}^{\circ+}\right)$ is generated by oxidation of ABTS with potassium persulfate and is reduced in the presence of hydrogendonating antioxidants into colourless form. Quantification was performed using the dose-response curve for reference antioxidant Trolox water soluble form of vitamin E. Robuvit antioxidant capacity was calculated as Trolox equivalents per mg of Robuvit. 
2.6. Determination of Advanced Oxidation Protein Products (AOPP). Serum concentration of AOPP was measured by modified method according to Witko-Sarsat et al. [20]. $200 \mu \mathrm{L}$ of blood serum diluted 1:5 with phosphate buffer saline (PBS, pH 7.4), $200 \mu \mathrm{L}$ of chloramine T $(0-100 \mu \mathrm{mol} / \mathrm{L})$ for calibration, and $200 \mu \mathrm{L}$ of PBS as blank were applied on a microtiter plate. $10 \mu \mathrm{L}$ of $1.16 \mathrm{~mol} / \mathrm{L}$ potassium iodide was added to standards and $20 \mu \mathrm{L}$ of acetic acid was added into all samples. Absorbance at $340 \mathrm{~nm}$ was measured and results are presented in $\mu \mathrm{mol} / \mathrm{L}$.

2.7. Determination of Protein Carbonyls. The concentration of protein carbonyls in plasma was measured by ELISA method according to Buss et al. [21]. Briefly, carbonyls of sample were derivatized by 2,4-dinitrophenylhydrazine (DNPH). A biotin-conjugated rabbit IgG raised against DNPH was used as a primary antibody and a monoclonal goat anti-rabbit IgG antibody labelled by horseradish peroxidase (HRP) as a secondary antibody. Product of enzymatic reaction catalyzed by HRP has absorption maximum at $490 \mathrm{~nm}$. Results were calculated from calibration curve using oxidized BSA as a standard and expressed in $\mathrm{ng} / \mathrm{mL}$.

2.8. Determination of Advanced Glycation End-Products (AGEs). The concentration of plasma AGEs was determined by modified method according to Kalousová et al. [22]. Determination was based on measurement of total fluorescence at wavelengths (exc./emis.) $345 \mathrm{~nm} / 465 \mathrm{~nm}$ in the plasma diluted with $0.01 \mathrm{~mol} / \mathrm{L}$ PBS. Results are expressed in AU/g of proteins.

2.9. Determination of Oxidative DNA Damage by Comet Assay. Oxidative DNA damage in lymphocytes was evaluated by the enzymatically modified comet assay using formamidopyrimidine DNA glycosylase (Fpg) recognizing oxidized purines [23]. Lymphocytes were isolated using Histopaque 1083 according to the manufacturer's protocol. Oxidative DNA damage was expressed as a number of 8-oxoG per $10^{6}$ guanines according to ESCODD [24].

2.10. Determination of 8-Isoprostanes (8-isoP). 8-isoP were determined by the commercial EIA kit (Cayman Chemical Company, USA). This assay is based on the competition between 8-isoP and an 8-isoprostane-acetylcholinesterase (AChE) conjugate (8-isoprostane Tracer) for a limited number of 8-isoprostane-specific rabbit antiserum binding sites. Because the concentration of the 8-isoprostane Tracer is held constant while the concentration of 8-isoP varies, the amount of 8-isoprostanes Tracer that is able to bind to the rabbit antiserum will be inversely proportional to the concentration of 8 -isoP in the well. The plate is washed to remove any unbound reagents and then Ellman's reagent (which contains the substrate to AchE) is added to the well. The product of enzymatic reaction has a distinct yellow colour and absorbs the light at $405 \mathrm{~nm}$. The concentration of 8 -isoP is expressed in $\mathrm{pg} / \mathrm{mL}$.

2.11. Determination of Lipid Peroxides (LP). Concentration of LP in serum was measured by method according to ElSaadani et al. [25]. The analysis was based on the ability of LP to convert iodide to iodine, which can be measured spectrophotometrically at $365 \mathrm{~nm}$. Results are presented in $\mathrm{nmol} / \mathrm{mL}$ of plasma.

2.12. Measurement of Activity of $\mathrm{Cu} / \mathrm{Zn}$-Superoxide Dismutase (SOD). Activity of SOD was determined by the commercial kit number 19160 (Fluka, Germany), using bovine $\mathrm{Cu} / \mathrm{Zn}$ SOD as a standard (Sigma, Germany). Superoxide radical is generated from xanthine and oxygen by xanthine oxidase. Superoxide radical reduces Dojindo's highly water-soluble tetrazolium salt, WST-1 (2-(4-iodophenyl)-3-(4-nitrophenyl)-5-(2,4-disulfophenyl)-2H-tetrazolium, monosodium salt) to form a yellow water-soluble formazan dye with maximum absorption at $450 \mathrm{~nm}$. At the presence of SOD the reduction of WST-1 is decreased. $1 \mathrm{U}$ of SOD activity is defined as the enzyme activity causing 50\% inhibition of reduction of WST-1. SOD activity is expressed in $\mathrm{U}$ SOD/mg $\mathrm{Hb}$.

2.13. Measurement of Activity of Catalase (CAT). Catalase activity was determined by modified method of Bergmeyer [26]. $250 \mu \mathrm{L}$ of $\mathrm{H}_{2} \mathrm{O}_{2}$ was added into $50 \mathrm{~mL}$ phosphate buffer saline (PBS, $50 \mathrm{mmol} / \mathrm{L}, \mathrm{pH}=7.0$ ) and formed mixture was diluted to get absorbance $0.7-1.0 .30 \mu \mathrm{L}$ of sample was added into $2 \mathrm{~mL}$ of $\mathrm{PBS}+\mathrm{H}_{2} \mathrm{O}_{2}$ mixture. Change of absorbance at wavelength $240 \mathrm{~nm}$ was measured for $1 \mathrm{~min}$. Distilled water was used as blank. Activity of catalase is expressed in $\mu \mathrm{kat} / \mathrm{g}$ $\mathrm{Hb}$.

2.14. Measurement of Activity of Glutathione Peroxidase (GPx). Activity of GPx was determined by the commercial kit (Sigma-Aldrich, USA). This kit uses an indirect determination method. It is based on the oxidation of glutathione (GSH) to oxidized glutathione (GSSG) catalyzed by GPx, which is then coupled to the recycling of GSSG back to GSH utilizing glutathione reductase and NADPH. The decrease in NADPH absorbance measured at $340 \mathrm{~nm}$ during the oxidation of NADPH to $\mathrm{NADP}^{+}$is indicative of GPx activity. Activity of GPx is expressed in $\mathrm{U} / \mathrm{g} \mathrm{Hb}$.

2.15. Measurement of Total Antioxidant Capacity of PlasmaORAC (Oxygen Radical Absorbance Capacity) Assay. The ORAC assay was measured by modified method according to Huang et al. [27]. The method is based on the oxygen radical absorbance capacity where a peroxyl radical (AAPH) oxidizes fluorescein in competition with an antioxidant (in the plasma). AAPH leads to production of $\mathrm{ROO}^{-}$that reacts with the fluorescein. This results in a gradual loss of fluorescence intensity. Antioxidants, which are present in the plasma, inhibit the reaction between $\mathrm{ROO}^{-}$and the fluorescent probe, which slows down or inhibits the fluorescence degradation. The ORAC assay indicates the antioxidant capacity of the plasma by using the area under the curve in combination with inhibition time and inhibition potency. Results are presented as mmol of Trolox/L.

2.16. Measurement of Total Antioxidant Capacity-FRAP (Ferric Reducing Ability of Plasma) Assay. The FRAP was determined by the method according to Benzie and Strain [28]. 
The method is based on the reduction of $\mathrm{Fe}^{3+}$-TPTZ complex to the ferrous form at low $\mathrm{pH}(\mathrm{pH}$ 3.6). This reduction is monitored spectrophotometrically at $593 \mathrm{~nm}$. Quantification was performed using the dose-response curve for reference antioxidant Trolox. Results are presented as mmol of Trolox $/ \mathrm{mL}$.

2.17. Statistical Analysis. Results are presented as a mean \pm standard deviation (SD) or median and interquartile range (IQ, 1st quartile, 3rd quartile). Parametric Student's paired $t$-test was used for statistical analysis of data with a Gaussian distribution and nonparametric Mann-Whitney $U$ test or Wilcoxon's signed ranks test was used for data with a non-Gaussian distribution. Value $P<0.05$ was considered statistically significant. Statistical software StatsDirect 2.3.7. (StatsDirect Sales, Sale, Cheshire M33 3UY, UK) was used.

\section{Results}

Administration of Robuvit for 4 weeks decreased weight of volunteers, but because of high interindividual variability of body weight this change $(-0.7 \mathrm{~kg})$ has no relevance. Values of BMI were not significantly changed after week 4 and week 6 .

Basic biochemical parameters were investigated in fasting venous blood in examination periods 0,4 , and 6: bilirubin, glucose, GMT, ALP, AST, ALT, UA, TP, TCh, TAG, HDLchol, LDL-chol, and VLDL-chol. All values of mentioned biochemical parameters were in the physiological ranges.

We did not observe serious unwanted effects of Robuvit administration.

In vitro antioxidant capacity of Robuvit was calculated as 6.37 micromole Trolox equivalent/mg of Robuvit.

Concentrations of markers of oxidative damage to proteins (AOPP, protein carbonyls, and AGEs), DNA (8-oxoG), and lipids (8-isoP and LP), activities of antioxidant enzymes (SOD, CAT, and GPx), and total antioxidant capacity (ORAC and FRAP) are summarized in Table 1. Four weeks administration of Robuvit significantly decreased the concentration of AOPP in serum by $42.09 \%$ and LP by $21.53 \%$. This effect persisted after week 6 where the level of AOPP remained decreased by $42.85 \%$ and LP by $19.79 \%$.

The concentrations of protein carbonyls, AGEs, 8-oxoG, and 8 -isoP were not significantly changed after week 4 . Only after week 6 we found out significantly decreased level of protein carbonyls by $7.77 \%$ in comparison to week 0 .

We measured activities of SOD, CAT, and GPx in haemolysate of erythrocytes. Administration of Robuvit significantly increased activity of SOD by $11.76 \%$ and this effect persisted after week 6 where the activity of SOD was even more increased by $13.22 \%$. We also found a significantly higher activity of CAT after week 4 by $15.54 \%$. Activity of GPx was not influenced by intake of Robuvit.

Total antioxidant capacity of plasma was determined by two methods with different mechanism of action: ORAC and FRAP. We did not find significant changes in ORAC values in weeks 4 and 6 in comparison to week 0 . However, we found out significantly increased level of FRAP values by $6.31 \%$ after week 4 .

\section{Discussion}

We have studied in vitro antioxidant capacity of the French oak wood extract Robuvit and the in vivo effect of its administration on markers of oxidative damage to biomolecules, activity of antioxidant enzymes, and total antioxidant capacity in 20 healthy volunteers. Our results represent the first investigation of extract from the wood of Quercus robur, Robuvit on oxidative stress in humans.

We have determined in vitro antioxidant capacity of Robuvit by TEAC method. Natella et al. [3] determined the antioxidant capacity of Robuvit by ORAC assay as $648 \mathrm{nmol}$ Trolox equivalents per mg extract in Robuvit, 10 times lower than our result ( $6370 \mathrm{nmol}$ Trolox equivalents per mg), which can be caused by different method used or rather by different way of evaluation.

In our human trial we have found that Robuvit was able to protect significantly proteins and lipids against oxidation as we found significantly decreased levels of AOPP and LP in serum.

In addition, 4-week intake of Robuvit significantly increased the intracellular defence against oxidative stress by enhancing the activities of SOD and CAT in erythrocytes. We also found significantly increased FRAP values of total antioxidant capacity in the plasma (by 6.3\%) after week 4 in healthy volunteers, but this small change may not have a biological relevance. Also Natella et al. [3] observed significantly increased total antioxidant capacity in the hydrophilic component of plasma (by 5.55\%) measured by ORAC assay.

The mechanism for the antioxidant effect of polyphenols in Robuvit in vivo is most probably based on the antioxidant and biomodulating activity of the EA and metabolites of the roburins, the urolithins.

Following consumption of the oak wood extract Robuvit, besides EA and GA, three different urolithins were identified in plasma of volunteers [3]. Antioxidant effects of EA and urolithins were examined in many models in vivo and in vitro. They were associated with reduction of intracellular reactive oxygen species (ROS) and malondialdehyde (MDA) levels and increase of SOD activity in $\mathrm{H}_{2} \mathrm{O}_{2}$-treated T24 cells [9]. Similar results were observed also by Kim et al. [8] who found out that EA significantly reduced ROS level and MDA concentration in paraquat-induced A549 cells. Kavitha et al. [7] observed significant increased expression of antioxidant enzymes SOD, CAT, and GPx by EA in 7,12-dimethylbenz[a]anthracene- (DMBA-) induced hamster buccal pouch carcinogenesis model. Celik et al. [6] also found significantly increased activities of CAT and GPx in rat liver microsomes by $\mathrm{EA}$ treatment. Urolithins accumulate in different tissues of the body and they have been suggested to be responsible for biological effects observed as a consequence of the ingestion of ellagitannins-rich foods [29]. Our results show rather indirect antioxidant effects of Robuvit than direct ones. Although we observed significantly increased total antioxidant capacity, this change is too small to have important biological relevance. Robuvit increases antioxidant protection against oxidative damage to biomolecules probably through the stimulation of expression or activities of antioxidant enzymes, what is supported by 
TABLE 1: Markers of oxidative stress, activity of antioxidant enzymes, and total antioxidant capacity after weeks 0,4 , and 6 .

\begin{tabular}{|c|c|c|c|c|c|}
\hline Parameter & Week 0 & Week 4 & $P(0$ versus 4$)$ & Week 6 & $P(0$ versus 6$)$ \\
\hline $\mathrm{AOPP}(\mu \mathrm{mol} / \mathrm{L})$ & $58.06(49.32 ; 59.27)$ & $33.62(30.49 ; 35.56)$ & $<0.0001$ & $33.18(28.44 ; 34.03)$ & $<0.0001$ \\
\hline $\mathrm{PC}(\mathrm{ng} / \mathrm{mL})$ & $0.296 \pm 0.059$ & $0.288 \pm 0.052$ & n.s. & $0.273 \pm 0.054$ & 0.0037 \\
\hline AGEs (AU/g prot.) & $273.17(249.01 ; 305.33)$ & $296.17(237.34 ; 323.05)$ & n.s. & $286.07(258.07 ; 322.95)$ & n.s. \\
\hline 8-oxoG/10 $60^{6}$ & $0.61(0.35 ; 0.91)$ & $0.79(0.47 ; 1.43)$ & n.s. & $0.78(0.38 ; 1.62)$ & n.s. \\
\hline 8-isoP (pg/mL) & $24.59(21.16 ; 33.77)$ & $34.02(24.16 ; 39.01)$ & n.s. & $31.63(23.98 ; 44.66)$ & n.s. \\
\hline $\mathrm{LP}(\mathrm{nmol} / \mathrm{mL})$ & $42.55(33.6 ; 61.54)$ & $33.39(28.17 ; 44.19)$ & 0.0174 & $34.13(28.10 ; 48.37)$ & 0.0038 \\
\hline $\mathrm{SOD}(\mathrm{U} / \mathrm{mg} \mathrm{Hb})$ & $42.42 \pm 6.83$ & $47.41 \pm 9.93$ & 0.0198 & $48.03 \pm 5.27$ & 0.0240 \\
\hline CAT ( $\mu$ kat/g Hb) & $5.60(4.76 ; 6.12)$ & $6.47(6.11 ; 7.41)$ & 0.0012 & $4.59(3.72 ; 6.46)$ & n.s. \\
\hline GPx (U/g Hb) & $39.55 \pm 9.16$ & $40.74 \pm 8.23$ & n.s. & $36.21 \pm 8.96$ & n.s. \\
\hline ORAC (mmol/L) & $8.97(8.34 ; 9.61)$ & $8.72(8.03 ; 9.67)$ & n.s. & $8.69(8.08 ; 9.72)$ & n.s. \\
\hline FRAP $(\mathrm{mmol} / \mathrm{mL})$ & $0.586 \pm 0.098$ & $0.623 \pm 0.115$ & 0.0091 & $0.603 \pm 0.124$ & n.s. \\
\hline
\end{tabular}

Data are presented as mean \pm SD or median and IQ range (1st quartile; 3rd quartile); AOPP: advanced oxidation protein products; PC: protein carbonyls; AGEs: advanced glycation end-products; AU: arbitrary units; 8-isoP: 8-isoprostanes; LP: lipid peroxides; SOD: Cu/Zn-superoxide dismutase; CAT: catalase; GPx: glutathione peroxidase; ORAC: oxygen radical absorbance capacity; FRAP: ferric reducing ability of plasma; $P<0.05$ : significant; n.s.: not significant $(P>0.05)$.

increased activities of SOD and CAT after supplementation of Robuvit. However, precise mechanism of antioxidant effects is yet unknown and there are another studies needed.

\section{Conclusions}

In conclusion, we have confirmed for the first time that the intake of the French oak wood extract Robuvit is associated with a decreased damage to proteins and lipids, a stimulation of antioxidant enzymes (SOD and catalase), and a moderate increase of total antioxidant capacity of plasma in humans.

\section{Conflict of Interests}

The authors declare that there is no conflict of interests.

\section{Acknowledgments}

The study was partially supported by Horphag Res. Ltd. and by Mind and Health, Civil Association. The authors wish to thank Assoc. Professor P. Blazicek, PhD., for the assistance at basic biochemical parameters determination, a.o. Univ. Professor Karl-Heinz Wagner, PhD., for the assistance at ORAC measurement, Zuzana Kralovicova for FRAP determination and for technical and clinical assistance, D. Opalena, L. Chandogova, and E. Palaghyova.

\section{References}

[1] W. Mayer, W. Gabler, A. Riester, and H. Korger, "On tannins compounds from the wood of chestnut and oak wood-IIs. Isolation of castalagin, vescalagin, castalin and vescaline," Liebigs Annual of Chemistry, vol. 707, pp. 177-181, 1967.

[2] C. L. M. H. du Penhoat, V. M. F. Michon, S. Peng, C. Viriot, A. Scalbert, and D. Gage, "Structural elucidation of new dimeric ellagitannins from Quercus robur," Journal of the Chemical Society, no. 7, pp. 1653-1660, 1991.

[3] F. Natella, G. Leoni, M. Maldini et al., "Absorption, metabolism, and effects at transcriptome level of a standardized French oak wood extract, Robuvit , in healthy volunteers: pilot study,"
Journal of Agricultural and Food Chemistry, vol. 62, no. 2, pp. 443-453, 2014

[4] A. Glabasnia and T. Hofmann, "Sensory-directed identification of taste-active ellagitannins in American (Quercus alba L.) and European oak wood (Quercus robur L.) and quantitative analysis in bourbon whiskey and oak-matured red wines," Journal of Agricultural and Food Chemistry, vol. 54, no. 9, pp. 3380-3390, 2006.

[5] N. P. Seeram, S. M. Henning, Y. Zhang, M. Suchard, Z. Li, and D. Heber, "Pomegranate juice ellagitannin metabolites are present in human plasma and some persist in urine for up to 48 hours," The Journal of Nutrition, vol. 136, no. 10, pp. 2481-2485, 2006.

[6] G. Celik, A. Semiz, S. Karakurt, S. Arslan, O. Adali, and A. Sen, "A comparative study for the evaluation of two doses of ellagic acid on hepatic drug metabolizing and antioxidant enzymes in the rat," BioMed Research International, vol. 2013, Article ID 358945, 9 pages, 2013.

[7] K. Kavitha, P. Thiyagarajan, J. Rathna, R. Mishra, and S. Nagini, "Chemopreventive effects of diverse dietary phytochemicals against DMBA-induced hamster buccal pouch carcinogenesis via the induction of Nrf2-mediated cytoprotective antioxidant, detoxification, and DNA repair enzymes," Biochimie, vol. 95, no. 8, pp. 1629-1639, 2013.

[8] Y. S. Kim, T. Zerin, and H. Y. Song, "Antioxidant action of ellagic acid ameliorates paraquat-induced A549 cytotoxicity," Biological and Pharmaceutical Bulletin, vol. 36, no. 4, pp. 609-615, 2013.

[9] Z. Qiu, B. Zhou, L. Jin et al., "In vitro antioxidant and antiproliferative effects of ellagic acid and its colonic metabolite, urolithins, on human bladder cancer T24 cells," Food and Chemical Toxicology, vol. 59, pp. 428-437, 2013.

[10] Y. Chung, L. Lu, M. Tsai, Y. Chen, S. Yao, and C. Hsu, "The inhibitory effect of ellagic acid on cell growth of ovarian carcinoma cells," Evidence-Based Complementary and Alternative Medicine, vol. 2013, Article ID 306705, 12 pages, 2013.

[11] S. Umesalma, P. Nagendraprabhu, and G. Sudhandiran, "Antiproliferative and apoptotic-inducing potential of ellagic acid against 1,2-dimethyl hydrazine-induced colon tumorigenesis in Wistar rats," Molecular and Cellular Biochemistry, vol. 388, no. 1-2, pp. 157-172, 2014. 
[12] L. Vanella, C. di Giacomo, R. Acquaviva et al., "Effects of ellagic acid on angiogenic factors in prostate cancer cells," Cancers, vol. 5, no. 2, pp. 726-738, 2013.

[13] M. Zhao, S. Tang, J. L. Marsh, S. Shankar, and R. K. Srivastava, "Ellagic acid inhibits human pancreatic cancer growth in Balb c nude mice," Cancer Letters, vol. 337, no. 2, pp. 210-217, 2013.

[14] M. R. Loizzo, A. Said, R. Tundis et al., "Antioxidant and antiproliferative activity of Diospyros lotus L. extract and isolated compounds," Plant Foods for Human Nutrition, vol. 64, no. 4, pp. 264-270, 2009.

[15] M. Marín, R. M. Giner, J. L. Ríos, and M. C. Recio, "Intestinal anti-inflammatory activity of ellagic acid in the acute and chronic dextrane sulphate sodium model of mice colitis," Journal of Ethnopharmacology, vol. 150, no. 3, pp. 925-934, 2013.

[16] M. A. Rosillo, M. Sánchez-Hidalgo, A. Cárdeno et al., "Dietary supplementation of an ellagic acid-enriched pomegranate extract attenuates chronic colonic inflammation in rats," Pharmacological Research, vol. 66, no. 3, pp. 235-242, 2012.

[17] M. Larrosa, F. A. Tomás-Barberán, and J. C. Espín, “The dietary hydrolysable tannin punicalagin releases ellagic acid that induces apoptosis in human colon adenocarcinoma Caco-2 cells by using the mitochondrial pathway," Journal of Nutritional Biochemistry, vol. 17, no. 9, pp. 611-625, 2006.

[18] Y. Chang, W. Chen, K. Lin et al., "Novel bioactivity of ellagic acid in inhibiting human platelet activation," Evidence-Based Complementary and Alternative Medicine, vol. 2013, Article ID 595128, 9 pages, 2013.

[19] R. Re, N. Pellegrini, A. Proteggente, A. Pannala, M. Yang, and C. Rice-Evans, "Antioxidant activity applying an improved ABTS radical cation decolorization assay," Free Radical Biology and Medicine, vol. 26, no. 9-10, pp. 1231-1237, 1999.

[20] V. Witko-Sarsat, M. Friedlander, C. Capeillère-Blandin et al., "Advanced oxidation protein products as a novel marker of oxidative stress in uremia," Kidney International, vol. 49, no. 5, pp. 1304-1313, 1996.

[21] H. Buss, T. P. Chan, K. B. Sluis, N. M. Domigan, and C. C. Winterbourn, "Protein carbonyl measurement by a sensitive ELISA method," Free Radical Biology and Medicine, vol. 23, no. 3, pp. 361-366, 1997.

[22] M. Kalousová, J. Škrha, and T. Zíma, "Advanced glycation endproducts and advanced oxidation protein products in patients with diabetes mellitus," Physiological Research, vol. 51, pp. 597604, 2002.

[23] A. R. Collins, V. L. Dobson, M. Dušinská, G. Kennedy, and R. Štětina, "The comet assay: what can it really tell us?" Mutation Research, vol. 375, no. 2, pp. 183-193, 1997.

[24] C. M. Gedik, A. Collins, and ESCODD, "Establishing the background level of base oxidation in human lymphocyte DNA: results of an interlaboratory validation study," The FASEB Journal, vol. 19, no. 1, pp. 82-84, 2005.

[25] M. El-Saadani, H. Esterbauer, M. El-Sayed, M. Goher, A. Y. Nassar, and G. Jurgens, "A spectrophotometric assay for lipid peroxides in serum lipoproteins using a commercially available reagent," Journal of Lipid Research, vol. 30, no. 4, pp. 627-630, 1989.

[26] H. U. Bergmeyer, Methods of Enzymatic Analysis, Volume III: Enzymes 1: Oxidoreductases, Transferases, Verlag Chemie, Weiheim, Germany, 1987.

[27] D. Huang, B. Ou, M. Hampsch-Woodill, J. A. Flanagan, and R. L. Prior, "High-throughput assay of oxygen radical absorbance capacity (ORAC) using a multichannel liquid handling system coupled with a microplate fluorescence reader in 96-well format," Journal of Agricultural and Food Chemistry, vol. 50, no. 16, pp. 4437-4444, 2002.

[28] I. F. F. Benzie and J. J. Strain, "The ferric reducing ability of plasma (FRAP) as a measure of 'antioxidant power': the FRAP assay," Analytical Biochemistry, vol. 239, no. 1, pp. 70-76, 1996.

[29] J. C. Espín, M. Larrosa, M. T. García-Conesa, and F. Tomás-Barberán, "Biological significance of urolithins, the gut microbial ellagic acid-derived metabolites: the evidence so far," Evidencebased Complementary and Alternative Medicine, vol. 2013, Article ID 270418, 15 pages, 2013. 


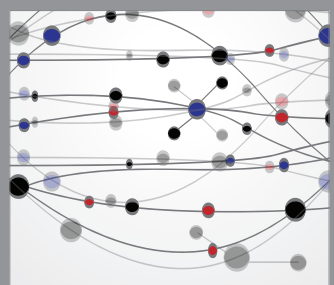

The Scientific World Journal
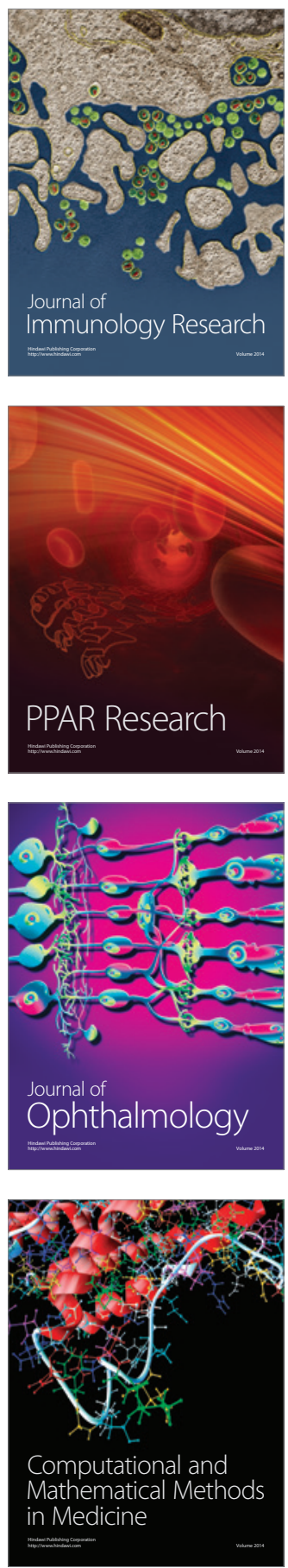

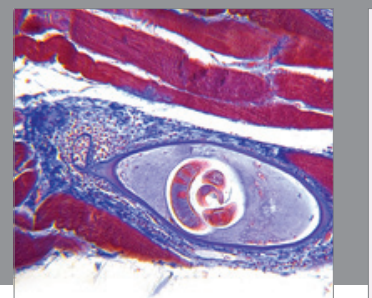

Gastroenterology

Research and Practice
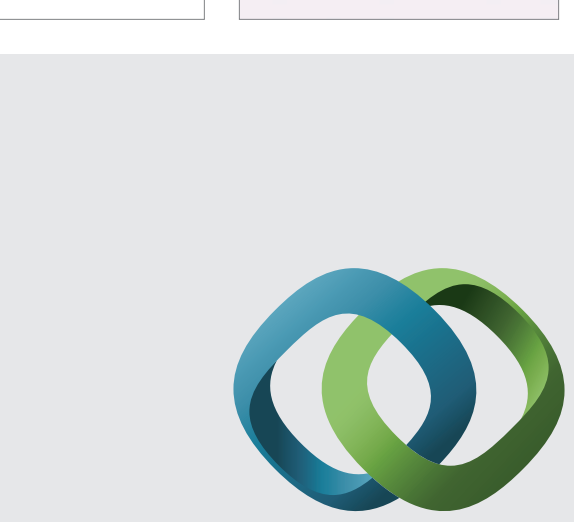

\section{Hindawi}

Submit your manuscripts at

http://www.hindawi.com
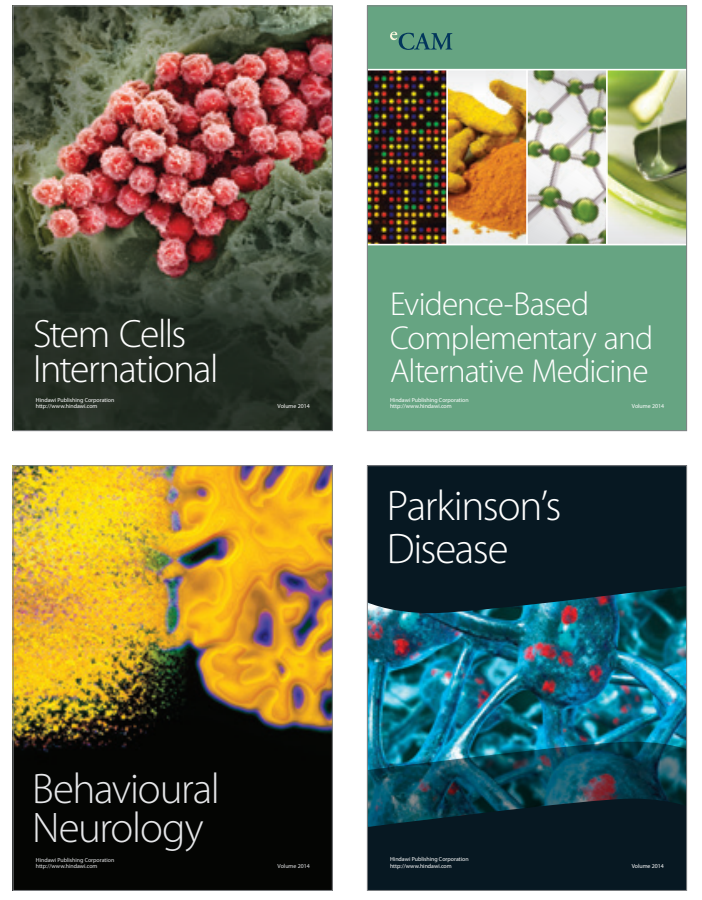
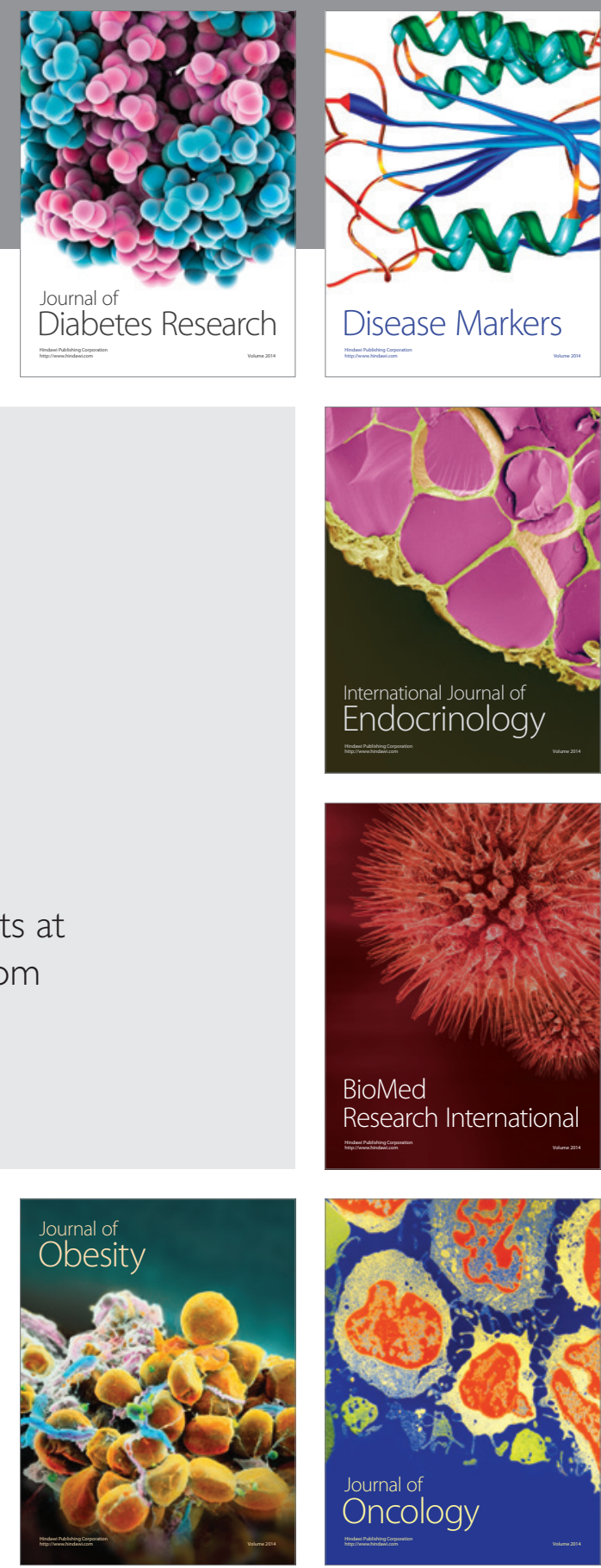

Disease Markers
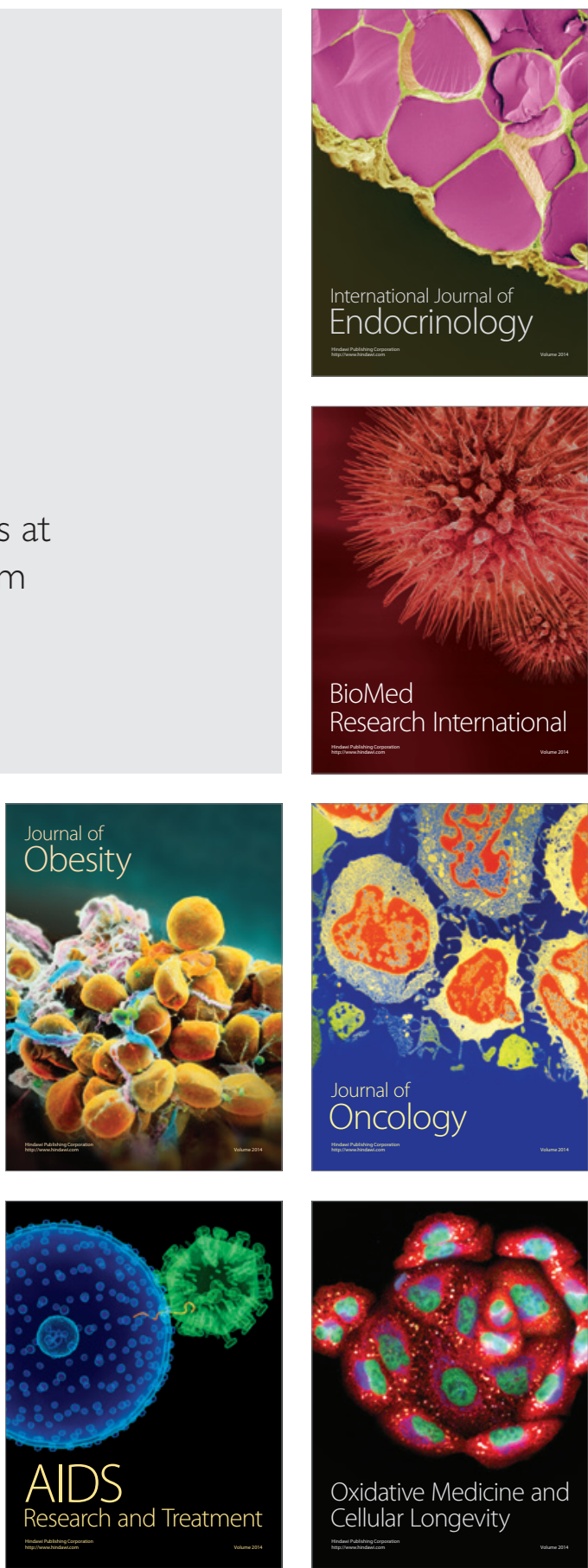